\title{
Synthesis of Poly(lauryl acrylate) by Single-Electron Transfer/Degenerative Chain Transfer Living Radical Polymerization Catalyzed by $\mathrm{Na}_{2} \mathrm{~S}_{2} \mathrm{O}_{4}$ in Water
}

Jorge F. J. Coelho, ${ }^{*}$ Erica Y. Carvalho, Dina S. Marques, Anatoliy V. Popov, Pedro M. Goncalves, Maria H. Gil

Living radical polymerization of lauryl acrylate was achieved by SET/DTLRP in water catalyzed by sodium dithionite. The work describes the synthesis of a highly hydrophobic and polar monomer in aqueous medium. The plots of $\bar{M}_{\mathrm{n}}$ versus conversion and $\ln [\mathrm{M}]_{0} /[\mathrm{M}]$ versus time are linear, indicating a controlled polymerization. This method leads to $\alpha, \omega$-diiodopoly(lauryl acrylate)s that can be further functionalized. The MWDs were determined using a combination of three detectors: RALLS, DV, and RI. The method studied in this work represents a possible route to prepare well-tailored macromolecules made of LA in environment friendly reaction medium. The syndiotactic content is $75 \%$.

\section{Introduction}

Poly(lauryl acrylate) (PLA) is widely used in many daily applications having an important commercial interest. Lauryl acrylate (LA) is extremely hydrophobic, nonpolar

J. F. J. Coelho, E. Y. Carvalho, D. S. Marques, M. H. Gil Chemical Engineering Department, University of Coimbra, Pólo II, Pinhal de Marrocos, 3030-290 Coimbra, Portugal Fax: +35 123979 8703; E-mail: jcoelho@eq.uc.pt J. F. J. Coelho, P. M. Goncalves

Cires S. A. - Companhia Industrial de Resinas Sintéticas, Apartado 20, Samoqueiro - Avanca, 3864-752 Estarreja, Portugal

A. V. Popov

Department of Radiology, University of Pennsylvania, Philadelphia, Pennsylvania 19104-6323, USA monomer used in several applications that require low affinity to water or good swelling properties in the oil. ${ }^{[1-3]}$ The long side chain of this monomer is known to play an important role in the kinetic behavior in the radical processes $^{[4]}$ and influence the crystallization of the polymer despite the syndiotacticity degree of the main chain. ${ }^{[5]}$ The homopolymers of acrylate have limited application areas, whereas their copolymers are of great potential utility. The structural features of the macromolecules play an important role in the performance of the final materials. ${ }^{[6]}$ Therefore, any strategy that allows the synthesis of well-defined macrostructures is essential to optimize the properties of the materials.

On this matter, the synthesis of PLA macroinitiators is extremely important as a possible route to prepare tailor-made materials. The traditional methods based on 
conventional free radical polymerization (FRP) are being substituted by new polymerization systems, due to the possibility of controlling the polymerization such as molecular weight, composition, and functionality. The living radical polymerization has been intensely studied in the last decade. Several techniques have been proposed to allow the control over molecular weight, molecular weight distribution, macromolecular architectures, and end-functional groups using at the same time a radical process. The most common strategies include reversible addition fragmentation chain transfer (RAFT), ${ }^{[7]}$ nitroxide-mediated living radical polymerization (NMP), ${ }^{[8]}$ and metal-catalyzed living radical polymerization. ${ }^{[9,10]}$ With regard to LA, this is the only reference available in literature. PLA was prepared via metal-catalyzed LRP by using $\mathrm{CuBr}$ complexed with $4,4^{\prime}$-di(5-nonyl)-2,2'-bipyridine ${ }^{[11]}$ in toluene at $90^{\circ} \mathrm{C}$. To the best of our knowledge, there are no reports about LRP of LA or any other acrylate with long chain side group (e.g., octadecyl, docosyl) in aqueous medium. The scalingup of the process under feasible industrial conditions has not still been approached. The investigation and development of methods that involve commercial available compounds, both inexpensive and easy to handle, are extremely important to foresee the industrial implementation of the LRP processes. The aim of the present work was to study the synthesis of PLA by single-electron transfer/degenerative chain transfer-mediated living radical polymerization (SET/DTLRP) undertaken in water. This method provides the reversible activation/deactivation step required to accomplish LRP by the combination of competitive SET and degenerative chain transfer. ${ }^{[12]}$ Discovered by Percec and coworkers, ${ }^{[12-14]}$ this strategy has proved to be effective in the polymerization of activated $^{[15,16]}$ and nonactivated monomers. ${ }^{[12,14,17-21]}$ This new technology has been studied with promising results considering its industrial implementation. ${ }^{[21-24]}$ Preliminary experiments leading to the activation of the chain ends were successfully carried out. The polymer solutions in THF were also characterized by multidetector size chromatography (TriSEC), determining by this way the relationship between the intrinsic viscosity versus molecular weight and radius of gyration versus molecular weight.

\section{Experimental Part}

\section{Materials}

THF HPLC-grade uninhibited, alumina oxide, iodoform (99\%), sodium dithionite ( $85 \%$ ) sodium bicarbonate $(99 \%)$, and LA were purchased from Sigma-Aldrich. LA was purified through a basic $\mathrm{Al}_{2} \mathrm{O}_{3}$ column; $p$-toluenesulfonic acid, sodium salt, hydrate (pTsNa) (98\%) were purchased form Acros Organics. The Poly- styrene standards were purchased from Polymer Laboratories. The hydroxypropyl methylcellulose Methocel F50 (MF50) was purchased from Dow Chemical Company. The partially hydrolyzed poly(vinyl alcohol) (PVA) was purchased from Syntomer. The other compounds were ordered from Sigma-Aldrich and used as received.

\section{Polymerization of LA via Single-Electron Transfer/ Degenerative Chain Transfer-Mediated Living Radical Polymerization}

The typical procedure was performed as described (example ratio $[\mathrm{LA}] /\left[\mathrm{CHI}_{3}\right]=100$ ). A $50 \mathrm{~mL}$ Ace Glass $8645 \# 15$ pressure tube equipped with bushing and plunger valve was charged with $9 \mathrm{~mL}$ of deionized water, $48.3 \mathrm{mg}$ of a $3 \%$ PVA solution ( $490 \mathrm{ppm}$ ), and $33.4 \mathrm{mg}$ of a $1.86 \%$ MF50 solution (210 ppm). The content was stirred and bubbled with nitrogen for $10 \mathrm{~min}$. Then the previously weighed catalyst $\left(\mathrm{Na}_{2} \mathrm{~S}_{2} \mathrm{O}_{4}, 76.5 \mathrm{mg}, 0.44 \mathrm{mmol}\right)$, initiator $\left(\mathrm{CHI}_{3}\right.$, $43.1 \mathrm{mg}, 0.11 \mathrm{mmol})$, buffer $\left(\mathrm{NaHCO}_{3}, 13.38 \mathrm{mg}, 0.16 \mathrm{mmol}\right)$, additive (pTsNa, $43.10 \mathrm{mg}, 0.22 \mathrm{mmol}$ ), and $3 \mathrm{~mL}$ (11 mmol) of purified LA were added into the tube. The tube was closed, frozen in $\mathrm{MeOH} / \mathrm{dry}$ ice and degassed through the plunger valve by applying circles of reduced pressure followed by filling the tube with inert gas for 20 times at $-40^{\circ} \mathrm{C}$. The valve was closed and the reaction was kept in a controlled-temperature water bath for $1 \mathrm{~h}$ at $35^{\circ} \mathrm{C}$ under stirring. At the end of the reaction, a small liquious part was taken for TriSEC measurements. The polymer was placed in a preweighted vial and the remaining part of the tube was carefully washed with THF and placed in a different vial. After drying in a vacuum oven until constant weight, both vials were weighed to determine the final conversion (24\%).

\section{Characterization Techniques}

The chromatography parameters of the samples were determined using an HPSEC; Viscotek (Dual detector 270, Viscotek, Houston, USA) with a differential viscometer (DV); right-angle laser-light scattering (RALLS, Viscotek); and refractive index (RI; Knauer $\mathrm{K}-2301)$. The column set consisted of a PL $10 \mu \mathrm{m}$ guard column $\left(50 \times 7.5 \mathrm{~mm}^{2}\right)$ followed by two MIXED-B PL columns $\left(300 \times 7.5 \mathrm{~mm}^{2}\right.$, $10 \mu \mathrm{m})$. HPLC pump (Knauer K-1001) was set with the flow rate of $1 \mathrm{~mL} \cdot \mathrm{min}^{-1}$. The eluent (THF) was previously filtered through a $0.2 \mu \mathrm{m}$ filter. The system was also equipped with a Knauer on-line degasser. The tests were done at $30^{\circ} \mathrm{C}$ using an Elder $\mathrm{CH}-150$ heater. Before the injection $(100 \mu \mathrm{L})$, the samples were filtered through a PTFE membrane with $0.2 \mu \mathrm{m}$ pore. The system was calibrated with narrow polystyrene standards. The differential RI of PLA for $670 \mathrm{~nm}$ was determined [refractive index increment $(\mathrm{d} n / \mathrm{d} c)=0.068]$. The analysis of light scattering data by Viscotek's software was done assuming that the second virial coefficient was 0 , considering the low solution concentrations used in this work. The ${ }^{1} \mathrm{H}$ NMR spectra $(500 \mathrm{MHz})$ were recorded in a Bruker DRX 500 spectrometer at $32{ }^{\circ} \mathrm{C}$ in $\mathrm{CDCl}_{3}$ with tetramethylsilane (TMS) as the internal standard. Diad tacticities of the polymer were determined from ${ }^{1} \mathrm{H}$ NMR as it was described elsewhere. ${ }^{[25]}$ Dynamical mechanical thermal analysis (DMTA) of thick specimens $\left(15.20 \times 7.45 \times 1.20 \mathrm{~mm}^{3}\right)$ was performed using a Triton Tritec 2000 in the constrain layer damping mode using two 
frequencies ( 1 and $10 \mathrm{~Hz}$ ), with the standard heating rate of $2{ }^{\circ} \mathrm{C} \cdot \min ^{-1}$. The $T_{\mathrm{g}}$ was determined as the peak in $\tan \delta\left(\tan \delta=E^{\prime \prime} /\right.$ $E^{\prime}$ ) where $E^{\prime \prime}$ and $E^{\prime}$ are the loss and storage modulus, respectively. The TGA curves were obtained using a Netzsch STA 449C Jupiter and the tests were carried out at $5^{\circ} \mathrm{C} \cdot \mathrm{min}^{-1}$.

\section{Calculation of Intrinsic Viscosity $[\eta]$ and Molecular Weight $\bar{M}_{\mathrm{w}}$}

The parameters presented in this work $\left(\bar{M}_{\mathrm{n}}\right.$ - number-average molecular weight, $\bar{M}_{\mathrm{w}}$ - weight-average molecular weight, $\eta$ intrinsic viscosity, $R_{\mathrm{g}}$ - radius of gyration, and $\mathrm{d} n / \mathrm{d} c$ ) were calculated using the TriSEC software provided by Viscotek (version 3.0). The algorithm applied in the software is briefly described in literature, ${ }^{[26]}$ and it will not be repeated here again. It should also be referred that the software monitors the elution times of the RALLS, DV, and RI detectors and adjusts the volume calculation according to the RI detector. The accuracy and precision of the Viscotek equipment was tested before injecting the samples using the procedure described elsewhere. ${ }^{[27]}$

\section{Results and Discussion}

\section{Simplified Mechanism}

The simplified mechanism involved in the SET/DTLRP ${ }^{[12]}$ of LA is presented in Scheme 1.

The SET/DTLRP provides the reversible activation/ deactivation step required to carry out the LRP mechanism using a combination of competitive SET and DT mechanism. ${ }^{[12]}$ The iodoform is reduced [Equation (3)] by the $\mathrm{SO}_{2}^{\bullet-}$ radical anion, which is formed from the dissociation of $\mathrm{S}_{2} \mathrm{O}_{4}^{2-}$ [Equation (1) and (2)], leading to the formation of radical $\mathrm{CHI}_{2}^{\circ}$. The other main reaction steps of this mechanism include the propagation [Equation (4) and (8)], DT to initiator or dormant species [Equation (5), (7), (9) and (10)], activation of dormant species mediated by radical anion $\mathrm{SO}_{2}^{\bullet-}$ [Equation (6)], and a possible termination by recombination [Equation (11)]. The polymer molecules formed by the latter process will be still active as they contain two active $-\mathrm{CHIC}(\mathrm{O}) \mathrm{OC}_{12} \mathrm{H}_{25}$ chain ends and the functionality of poly(LA) remains 2.0. The polyacrylate synthesized by this synthetic method is telechelic $\alpha, \omega$ diiodopoly(lauryl acrylate) [ $\alpha, \omega$-di(iodo)PLA].

\section{Kinetic Studies}

The kinetic experiments described in this publication were carried out in a $50 \mathrm{~mL}$ glass high-pressure tube equipped with a magnetic stirring bar. Each point depicted in the kinetic plots represents a single experiment.

SET/DTLRP of LA was carried out in water media containing $\mathrm{NaHCO}_{3}$ as a buffer and was catalyzed by $\mathrm{Na}_{2} \mathrm{~S}_{2} \mathrm{O}_{4}$.
The initiator was iodoform that is a bifunctional initiator in $\mathrm{Na}_{2} \mathrm{~S}_{2} \mathrm{O}_{4}$ mediated SET/DTLRP. ${ }^{[12]}$ This polymerization system proved to be efficient for the polymerization of vinyl chloride, ${ }^{[12]}$ 2-ethylhexyl acrylate, ${ }^{[18]}$ tert-butyl acrylate, ${ }^{[18]}$ and butyl acrylate ${ }^{[20]}$ as well as block copolymerization of vinyl chloride and butyl acrylate ${ }^{[21,22,24]}$ in water at room temperature. For that purpose, the $\mathrm{C}-\mathrm{I}$ bond should be labile enough to allow the transfer and the $\mathrm{R}$ (acrylate group) should stabilize the resulting radical through inductive and resonance effects. ${ }^{[28]}$ The suggested mechanism of SET/DTLRP was previously published and for that reason is not repeated here. ${ }^{[20]}$ Unlike other systems based on the DT mechanism, ${ }^{[28-31]}$ in the SET/DTLRP the activation also results from a SET between the $\mathrm{SO}_{2}^{\bullet-}$ radical anion and the iodine containing compounds. This different approach is more desirable from the chemical point of view since contrary to conventional initiators, the compound used $\left(\mathrm{Na}_{2} \mathrm{~S}_{2} \mathrm{O}_{4}\right)$ to reduce the active chain ends $\left(\mathrm{CHI}_{3},-\mathrm{CHI}_{2},-\mathrm{CHClI}\right)$ leading to the propagating radicals, does not initiate a polymer chain. Therefore, the control over the polymerization and the percentage of active chain ends, related to the total polymer chain ends are enhanced. The conventional initiators will always originate dead chain ends resulting from fragments of the initiator used.

The points in the kinetic plots (Figure 1) were obtained gravimetrically according to the procedure described (vide supra).

Figure 1(a) shows the kinetic plots for $\mathrm{Na}_{2} \mathrm{~S}_{2} \mathrm{O}_{4}$ / $\mathrm{NaHCO}_{3}$-catalyzed LRP of LA prepared at $35{ }^{\circ} \mathrm{C}$ under the following conditions: $[\mathrm{LA}]_{0} /\left[\mathrm{CHI}_{3}\right]_{0} /\left[\mathrm{Na}_{2} \mathrm{~S}_{2} \mathrm{O}_{4}\right]_{0} /[\mathrm{pTsNa}]_{0} /$ $\left[\mathrm{NaHCO}_{3}\right]_{0}=100: 1: 4: 2: 1.45$ by mol; [MethocelF50]/[PVA 88] $=$ 210:490 (wt.-ppm relative to LA).

The kinetic data exhibit two different slopes on the $\ln [M]_{0} /[M]$ versus polymerization time. The first slope $k_{\mathrm{p} 1}=0.942 \mathrm{~h}^{-1}$ represents the region where monomer diffusion is not limited by the viscosity of the reaction mixture. With the increase in monomer conversion, the reaction medium becomes more viscous and eventually leads to the formation of a solid phase. This process leads to the appearance of a second stage that presents a kinetic constant $\left(k_{\mathrm{p} 2}\right)$ several times lower than $k_{\mathrm{p} 1}$. The described trend was also observed in the cases of SET/DTLRP of other monomers as vinyl chloride, ${ }^{[12-14,18,23]}$ 2-ethylhexyl acrylate, ${ }^{[18]}$ tert-butyl acrylate, ${ }^{[18]}$ and butyl acrylate. ${ }^{[20]}$ The termination reactions can be neglected since the kinetic results show a first-order kinetics of the reaction relatively to the monomer concentration. Such behavior is observed for the kinetics presented in this paper regardless of the ratio [monomer]/[initiator] considered (Figure 1 and 2). Furthermore, the results suggest a linear dependence of the molecular weight determined by TriSEC $\left(\bar{M}_{n, T r i S E C}\right)$ versus the theoretical molecular weight $\left(\bar{M}_{n, t h}\right)$. These two features of the SET/DTLRP of LA support the living polymerization mechanism. As expected, the reaction rate 


$$
\begin{aligned}
& \mathrm{Na}_{2} \mathrm{~S}_{2} \mathrm{O}_{4} \stackrel{\text { water }}{\longrightarrow} 2 \mathrm{Na}^{+}+\mathrm{S}_{2} \mathrm{O}_{4}{ }^{2-} \\
& \mathrm{S}_{2} \mathrm{O}_{4}{ }^{2-} \stackrel{\text { interface }}{=} 2 \mathrm{SO}_{2}^{*-} \\
& \mathrm{CHI}_{3}+\mathrm{SO}_{2}{ }^{-} \stackrel{\mathrm{SET}}{\longrightarrow} \mathrm{CHI}_{2}^{\bullet}+\mathrm{I}^{-}+\mathrm{SO}_{2}
\end{aligned}
$$

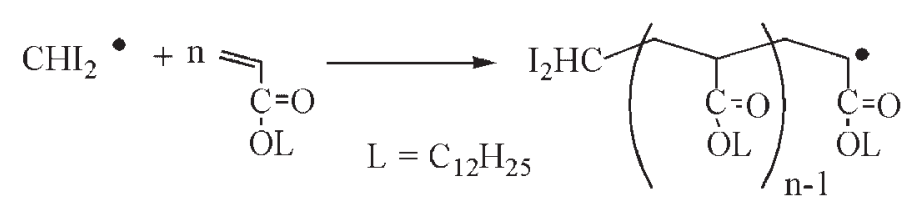

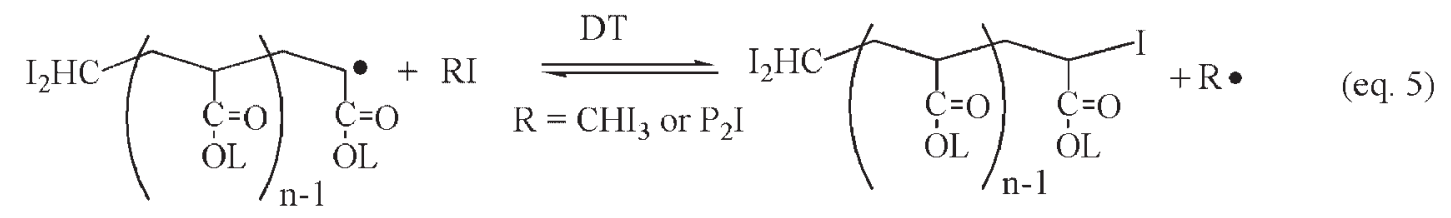

$$
\mathrm{P}_{1} \widehat{\mathrm{I}}^{\mathrm{I}}+\mathrm{SO}_{2} \cdot-\stackrel{\mathrm{SET}}{\longrightarrow} \mathrm{P}_{1} \widehat{\mathrm{I}}^{*}+\mathrm{I}^{-}+\mathrm{SO}_{2}
$$

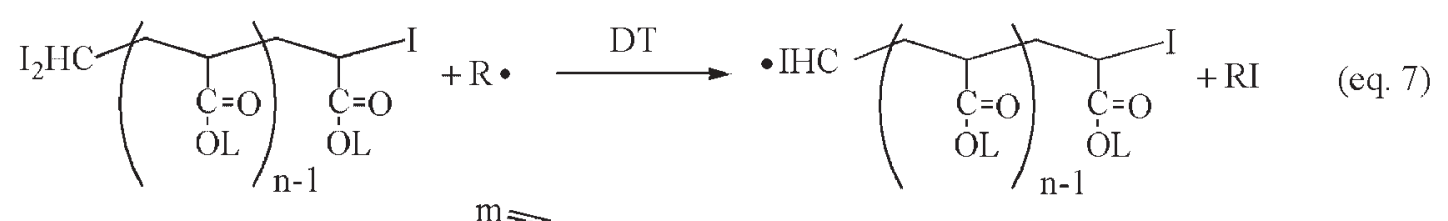

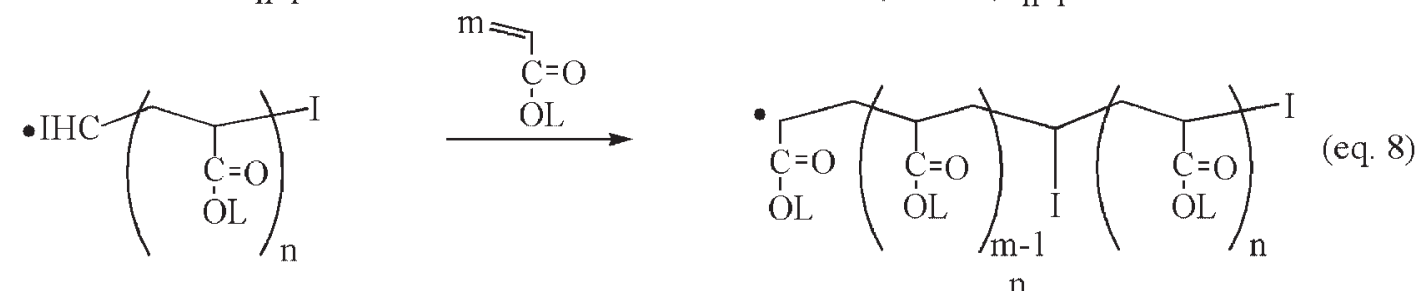

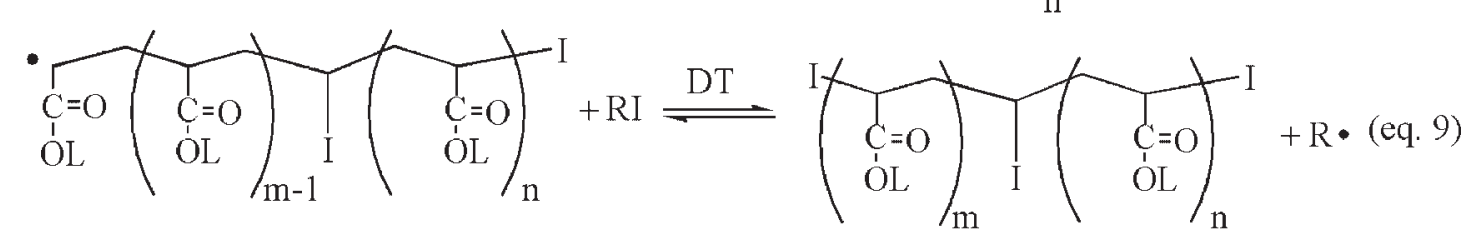

$$
\mathrm{P}_{1} \overbrace{\mathrm{I}}^{\mathrm{I}}+\mathrm{P}_{2} \cdot \stackrel{\mathrm{DT}}{=} \mathrm{P}_{2} \mathrm{I}+\mathrm{P}_{1} \overbrace{\mathrm{I}}^{\mathrm{I}^{\prime}}
$$

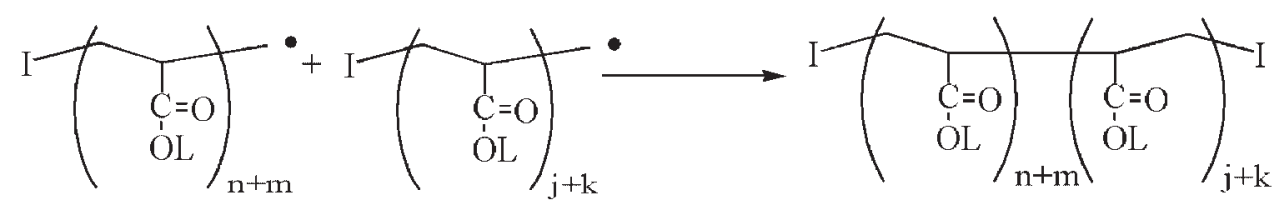

Scheme 1. Simplified mechanism of SET/DTLRP of LA. 
a) $[\mathrm{LA}]_{0} /\left[\mathrm{CH}_{3}\right]_{0} /\left[\mathrm{Na}_{2} \mathrm{~S}_{2} \mathrm{O}_{4}\right]_{0} /[\mathrm{pTs} \mathrm{Na}] /\left[\mathrm{NaHCO}_{3}\right]_{0}=100 / 1 / 4 / 2 / 1.45,35^{\circ} \mathrm{C}$

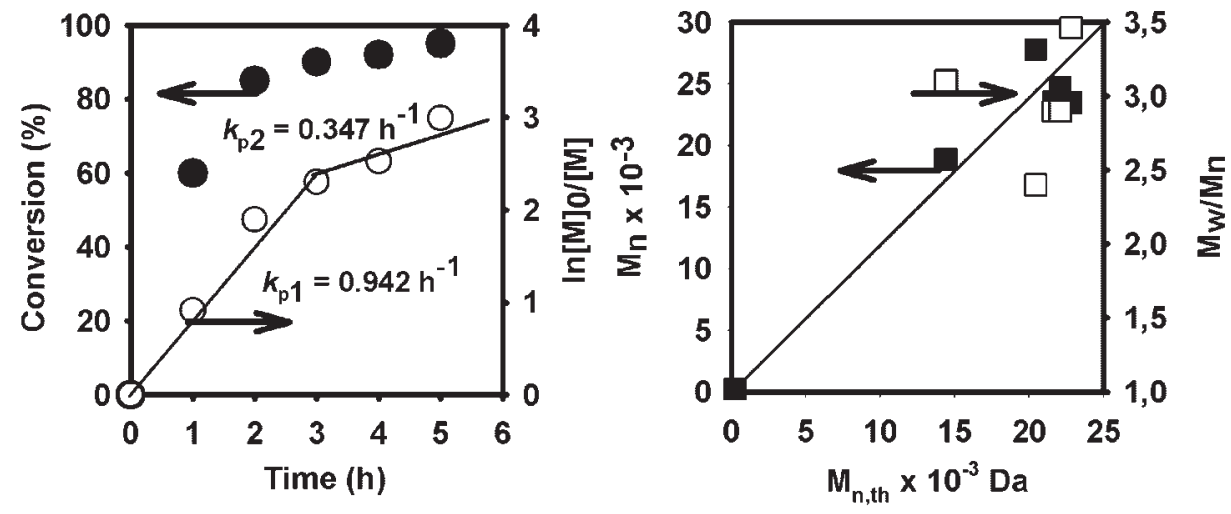

b) $\left.[\mathrm{LA}]_{0} /\left[\mathrm{CHI}_{3}\right]_{0} /\left[\mathrm{Na}_{2} \mathrm{~S}_{2} \mathrm{O}_{4}\right]\right]_{0} /[\mathrm{pTsNa}] /\left[\mathrm{NaHCO}_{3}\right]_{0}=250 / 1 / 4 / 2 / 1.45,35^{\circ} \mathrm{C}$
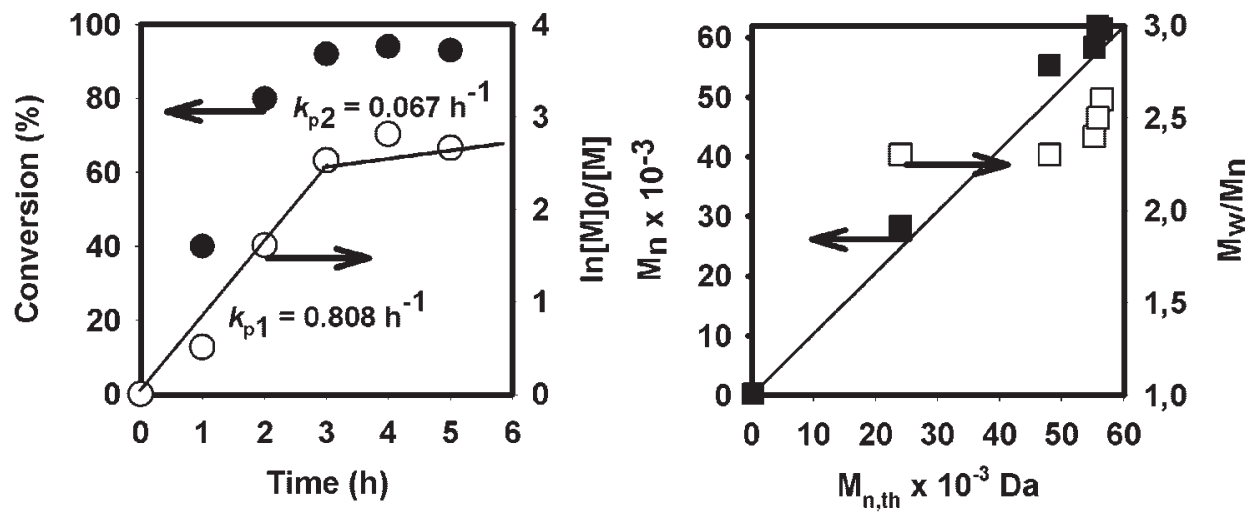

Figure 1. $\mathrm{Na}_{2} \mathrm{~S}_{2} \mathrm{O}_{4} / \mathrm{NaHCO}_{3}$-catalyzed LRP of LA initiated by iodoform in $\mathrm{H}_{2} \mathrm{O}$ in the presence of SA Methocel F5O and PVA 88, [LA] $/$ $\left[\mathrm{H}_{2} \mathrm{O}\right]_{0}=1: 3 \mathrm{v} / \mathrm{v}:$ (a) $[\mathrm{LA}]_{0} /\left[\mathrm{CH}_{3}\right]_{0} /\left[\mathrm{Na}_{2} \mathrm{~S}_{2} \mathrm{O}_{4}\right]_{0} /[\mathrm{pTsNa}]_{0} /\left[\mathrm{NaHCO}_{3}\right]_{0}=100: 1: 4: 2: 1.45$ by mol; $[$ MethocelF5o $/[$ PVA 88] $=210: 490$ (wt.-ppm relative to LA), $35^{\circ} \mathrm{C}$ and (b) $[\mathrm{LA}]_{0} /\left[\mathrm{CHI}_{3}\right]_{0} /\left[\mathrm{Na}_{2} \mathrm{~S}_{2} \mathrm{O}_{4}\right]_{\circ} /[\mathrm{pTsNa}]_{0} /\left[\mathrm{NaHCO}_{3}\right]_{0}=250: 1: 4: 2: 1.45$ by mol; $[\mathrm{Methocel}$ F50]/[PVA 88] $=210: 490$ (wt.-ppm relative to $L A), 35^{\circ} \mathrm{C}$.

decreases with the ratio monomer/initiator due to a reduced number of radicals for high DPs.

Following other results reported in the literature for SET/DTLRP systems, ${ }^{[18,20]}$ the polydispersity is relatively high and is justified by the heterogeneity of the medium.

The low polydispersity is not necessarily resulted from the living polymerization as described in the literature. ${ }^{[23,32]}$ The living system only requires the absence of any irreversible chain terminating reaction. To obtain a polymer with a narrow molar mass distribution, it is necessary to fulfill various requirements that are specific to each polymerization system. Several studies have been carried out on this subject, thus identifying five major conditions: ${ }^{[33-35]}$ (1) chain transfer or termination should be negligible; (2) the rate of propagation should be higher than the rate of depropagation; (3) the rate of initiation should be at least as fast as the rate of propagation; (4) the equilibrium created between the different species involved in the reaction that also have different reactivities should be fast; and (5) the system should be homogeneous with vigorous agitation.

Under the conditions mentioned, the polydispersity $\bar{M}_{\mathrm{W}} / \bar{M}_{\mathrm{n}}$ should decrease with conversion. When it increases, it is possible to identify the presence of chain breaking reactions. Living systems are not synonymous as with low polydispersity. The last requirement for low polydispersity described above, mostly related to the homogeneity of the system is impossible to achieve for LA polymerization when water is used as a continuous phase. The balance in this case will always be between a friendly reaction medium or the degree of control over the molecular weight distribution. Therefore, for industrial largescale production the desirable condition is to employ the water as a continuous phase. Moreover, the industry 
a) $[\mathrm{LA}]_{0} /\left[\mathrm{CHI}_{3}\right]_{0} /\left[\mathrm{Na}_{2} \mathrm{~S}_{2} \mathrm{O}_{4}\right]_{0} /[\mathrm{pTsNa}] /\left[\mathrm{NaHCO}_{3}\right]_{0}=500 / 1 / 4 / 2 / 1.45,35^{\circ} \mathrm{C}$
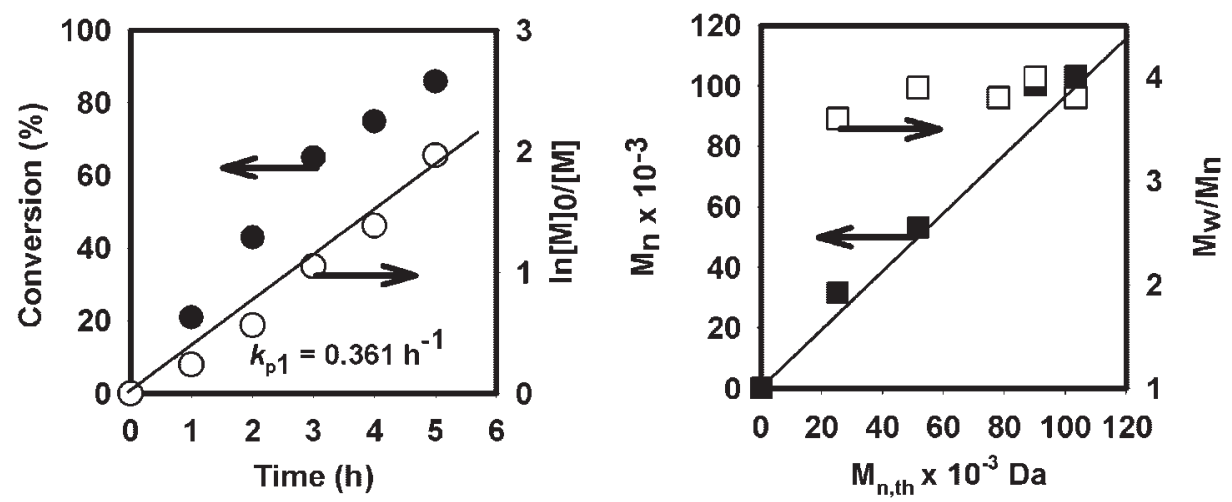

b) $\left.[\mathrm{LA}] 0 /\left[\mathrm{CH}_{3}\right]\right]_{0} /\left[\mathrm{Na}_{2} \mathrm{~S}_{2} \mathrm{O}_{4}\right] 0 /[\mathrm{pTsNa}] /\left[\mathrm{NaHCO}_{3}\right]_{0}=1000 / 1 / 4 / 2 / 1.45,35^{\circ} \mathrm{C}$
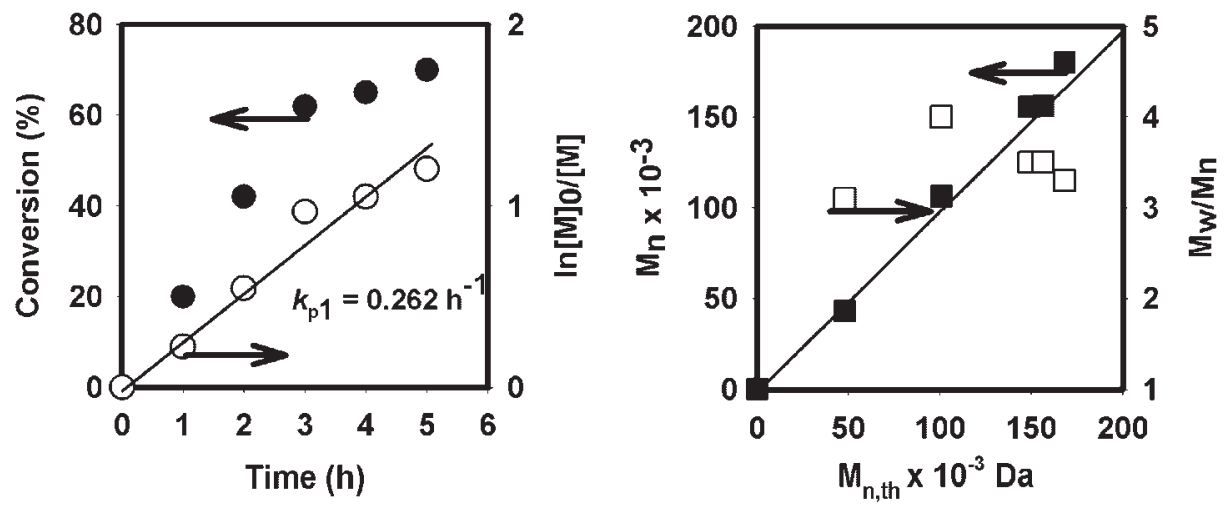

Figure 2. $\mathrm{Na}_{2} \mathrm{~S}_{2} \mathrm{O}_{4} / \mathrm{NaHCO}_{3}$-catalyzed LRP of LA initiated by iodoform in $\mathrm{H}_{2} \mathrm{O}$ in the presence of SA Methocel F5O and PVA 88, (a) [LA] $/\left[\mathrm{CHI}_{3}\right]_{0} /$ $\left[\mathrm{Na}_{2} \mathrm{~S}_{2} \mathrm{O}_{4}\right]_{\circ} /[\mathrm{pTsNa}]_{\circ} /\left[\mathrm{NaHCO}_{3}\right]_{\circ}=500: 1: 4: 2: 1.45$ by mol; [Methocel F5o]/[PVA 88] $=210: 490$ (wt.-ppm relative to LA), $35^{\circ} \mathrm{C}$ and (b) [LA] $/$ $\left[\mathrm{CHI}_{3}\right]_{\circ} /\left[\mathrm{Na}_{2} \mathrm{~S}_{2} \mathrm{O}_{4}\right]_{\circ} /[\mathrm{pTsNa}]_{\circ} /\left[\mathrm{NaHCO}_{3}\right]_{0}=1000: 1: 4: 2: 1.45$ by mol; [Methocel F5o $/\left[\right.$ PVA 88] $=210: 490$ (wt.-ppm relative to LA), $35^{\circ} \mathrm{C}$.

is used to deal with polymers with high polydispersity for decades that were prepared by conventional radical processes. ${ }^{[36]}$ Based on the above information, it is easy to understand the high polydispersity values observed.

\section{Structural Analysis of the PLA by $500 \mathrm{MHz}{ }^{1} \mathrm{H}$ NMR Spectroscopy}

Figure 3 shows the ${ }^{1} \mathrm{H}$ NMR spectrum of the PLA with $\bar{M}_{\text {n,TriSEC }}=23438 \mathrm{Da}$ prepared by SET/DTLRP at $35^{\circ} \mathrm{C}$. The protons in resonance are indicated in italics. The spectrum reveals the resonance of iodoform residue at $4.3 \mathrm{ppm}$, active chain ends signal at $5.0 \mathrm{ppm}$. Ester resonances are represented by the signals of $\alpha$-methylene group at 4.0 ppm, $\beta$-methylene group at $1.6 \mathrm{ppm}$ (overlapped with main chain signals); ${ }^{[25]}$ the rest nine methylene groups of lauryl demonstrate a strong signal at $1.3 \mathrm{ppm}$. Methyl group reveals resonance at $1.85 \mathrm{ppm}$. The assignment of main chain signals and tacticity measurement was made according to those for poly(butyl acrylate) by Tabuchi et al. $^{[25]}$ The methyne protons resonance is at $2.3 \mathrm{ppm}$. Meso-methylene groups have resonances at 1.9 and 1.45 ppm, correspondingly. Racemo-methylene groups reveal signal at $1.6 \mathrm{ppm}$. Methylene main chain resonances at 1.45 and $1.6 \mathrm{ppm}$ are overlapped with $\beta$-methylene of the ester group. The meso-content was measured by the comparison of integrals of methylene signal at $2.3 \mathrm{ppm}$ and one of meso-resonances at $1.9 \mathrm{ppm}$. This revealed the ratio $\mathrm{r} / \mathrm{m}=$ $75: 25$ for the PLA obtained at $35^{\circ} \mathrm{C}$. Such a high syndiotacticity was observed for poly(butyl acrylate) and poly(ethyl acrylate) synthesized by anionic polymerization at low temperatures in the presence of bulky Lewis acids. ${ }^{[25]}$ For PLA, this result demonstrates that long lauryl 


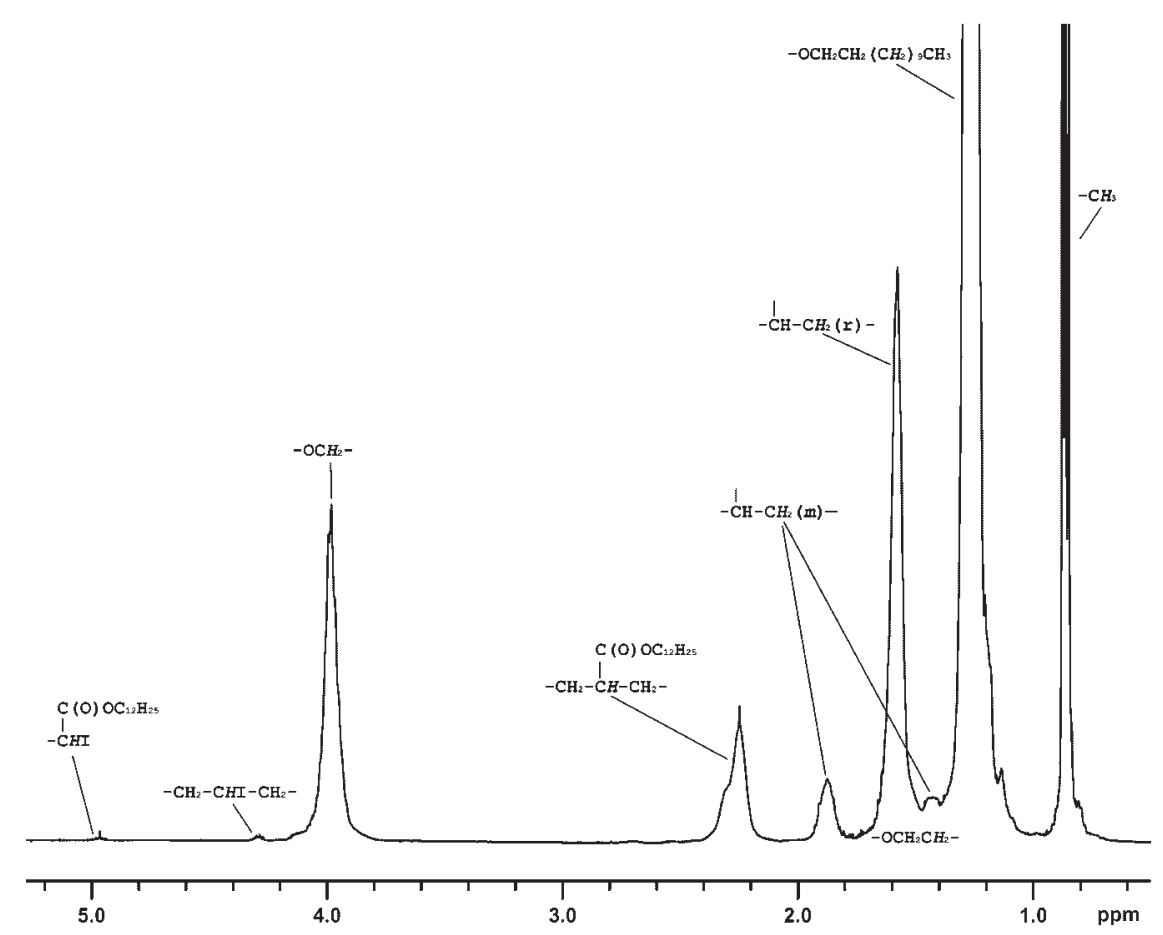

Figure 3. $500 \mathrm{MHz}{ }^{1} \mathrm{H}$ NMR spectra in $\mathrm{CDCl}_{3}$ of obtained $\alpha$, $\omega$-diiodoPLA SET/DTLRP at $35^{\circ} \mathrm{C}$.

fragment dramatically increases syndiotacticity of the polymer.

\section{SET/DTLRP of LA Initiated from $\alpha, \omega$-Diiodopoly(lauryl acrylate)}

The living character of the macroinitiator of PLA prepared by SET/DTLRP was evaluated considering the Szwarc's definition of a living polymer. ${ }^{[37-39]}$ Living polymers are the polymers that retain their ability to propagate for a long time and grow to a desired maximum size while their degree of termination or chain transfer is still negligible. Therefore, the living character of PLA was confirmed by a reinitiation experiment that produced PLA of $\bar{M}_{\text {n,TrisEC }}=$ 96500 Da starting from a PLA of $\bar{M}_{n, \text { TriSEC }}=1800$ Da after $8 \mathrm{~h}$ of reaction at $35 \mathrm{C}$.

Figure 4 shows the variation in the $[\eta]$ with the $\bar{M}_{\mathrm{W}, \text { TriSEC }}$ of the PLA prepared by SET/DTLRP. The points used in this plot were obtained from different samples prepared at $35^{\circ} \mathrm{C}$. The mathematical relationship between the $[\eta]$ and $\bar{M}_{\mathrm{W}}$ is

$$
[\eta]=116 \times 10^{-5} \bar{M}_{\mathrm{w}}^{0.47}
$$

The only reference reports the MHS constants of PLA. The value proposed for $K$ was slightly different $\left(66.3 \times 0^{-5}\right)$ from the one obtained in this work. Although the $\alpha$ value (0.50) matches our value Figure 5 compares the viscosity of the PLA prepared by SET and by FRP (based on the $K$ and $\alpha$ constants available in the literature $\left.{ }^{[40]}\right)$.

The results presented in Figure 5 indicate that for same molecular weight the viscosity of the PLA prepared by SET/ DTLRP is higher. Such difference could be related to the method followed for the determination of the MHS constants, or to the high linearity of the PLA prepared by LRP technique, due to absence of side reactions. ${ }^{[12]}$

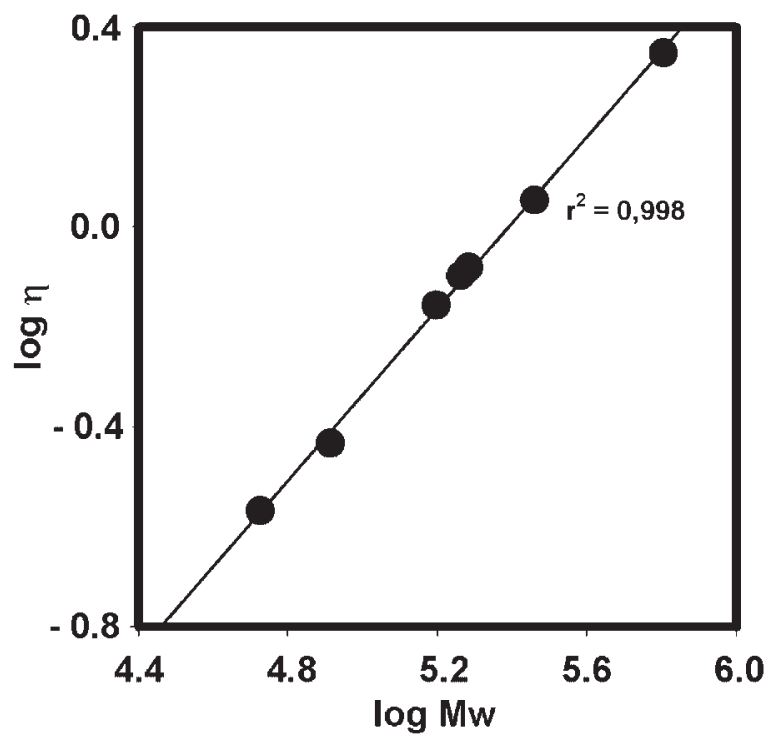

Figure 4. . Plot of log $[\eta]$ against $\log \left(\bar{M}_{\mathrm{w}}\right)$ for PLA prepared by SET/ DTLRP at $35^{\circ} \mathrm{C}$ from which the Mark-Houwink-Sakurada relationship was derived. 


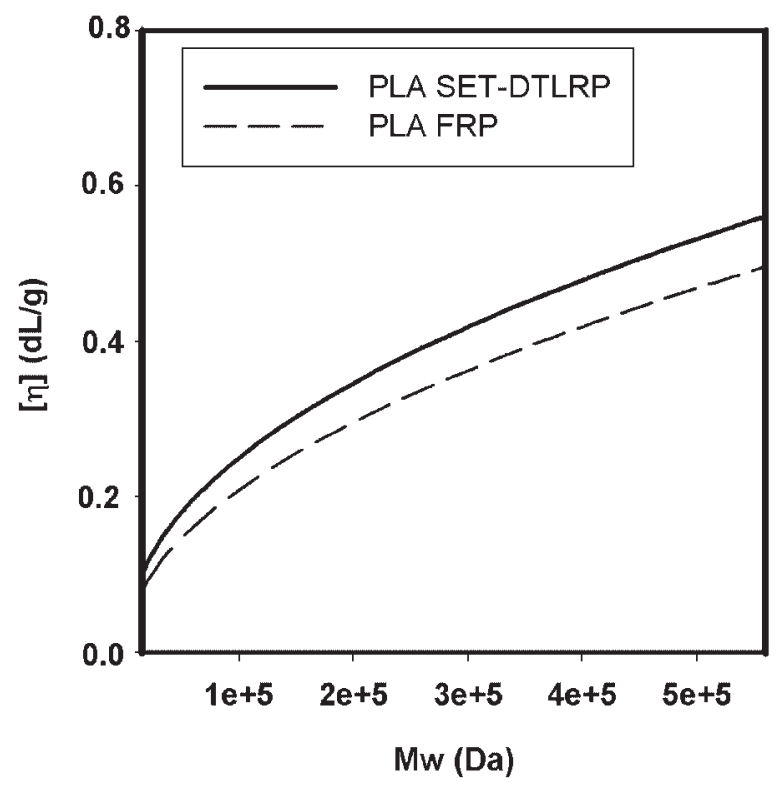

Figure 5. Variation of viscosity with the molecular weight for PLA prepared by SET/DTLRP and FRP.

Studies performed on the FRP of LA suggested that by using the conventional FRP method, the high molecular fractions of PLA remained without a significant degree of branching only when nonpolar solvents were used. ${ }^{[4]}$ With this approach the rate of diffusion-controlled termination step was diminished. In this work, it is shown that the SET/ DTLRP allows the preparation of the linear macrostructures even in polar solvents (water). Furthermore, the viscosity differences between the PLA prepared by SET/ DTLRP and FRP increase with the molecular weight.

The use of a viscosimeter detector in the TriSEC configuration is extremely useful for the determination of the size of molecules. These values can be related to the secondary structure of the polymer, either in terms of chain stiffness, conformation, or branching. Among the advantages that result from the characterization of MWD by SEC with multidetection is the possibility to determine parameters as the radius of gyration $\left(R_{\mathrm{g}}\right) \cdot{ }^{[27]}$ By definition, the $R_{\mathrm{g}}$ represents the root square average of the distance of the molecular segments of the chain from its center of gravity. $R_{\mathrm{g}}$ is used to express the molecular size and can only be determined rigorously from the initial slope of multiangle light scattering measurements, or alternatively can be computed from the intrinsic viscosity and molecular weight via the Ptitsyn-Eizner modification of Flory-Fox equation. ${ }^{[41]}$

$$
\begin{aligned}
& R_{\mathrm{g}}=\left(\frac{1}{6}\right)^{1 / 2}\left(\frac{[\eta] M}{\phi}\right)^{1 / 3} \\
& \phi=2.55 \times 10^{21}\left(1-2.63 \varepsilon+2.86 \varepsilon^{2}\right)
\end{aligned}
$$

Where $\varepsilon=\frac{2 a-1}{3}$ and $a$ is the Mark-Houwink exponent. The latter approach is certainly nonrigorous and inaccurate for polymer molecules that deviate significantly from the flexible coil model. ${ }^{[27]}$ Its knowledge is useful in determining the presence and extension of chain branches and when related to the $\bar{M}_{\mathrm{W}}$ is an important indication of chain stiffness. ${ }^{[27]}$ In the PLA macrostructure studies, this feature is even more important, since there is no data published related to this information.

The scaling relationship between the $R_{\mathrm{g}}$ and $\bar{M}_{\mathrm{W}}$ is presented in Figure 6. The $\log R_{\mathrm{g}}$ versus $\log \bar{M}_{\mathrm{w}}$ reveals a linear relation along the whole range of $\bar{M}_{\mathrm{w}}$ analyzed and can be described mathematically by the relation:

$$
R_{\mathrm{g}}=0.021 \times \bar{M}_{\mathrm{w}}^{0.52}
$$

To the best of our knowledge, there is no literature data dealing with constants of the $R_{\mathrm{g}}$ versus $\bar{M}_{\mathrm{W}}$ equation for PLA. The exponential constant obtained (0.52) suggests that the PLA adopts a coil conformation in solution. ${ }^{[26]}$

The glass transition temperature was determined by DMTA and is presented in Figure 7. The DMTA has been intensely used and recognized as a powerful tool to identify the material thermal transitions due to its extremely high sensibility. Its special sensibility to determine frequency-dependent transition, as the glass transition temperature that represents the motions of long-chain segments is of outstanding importance. The basic function of DMTA is to obtain information about the mechanical and thermal properties of the materials by applying a sinusoidal load to a specimen and measuring

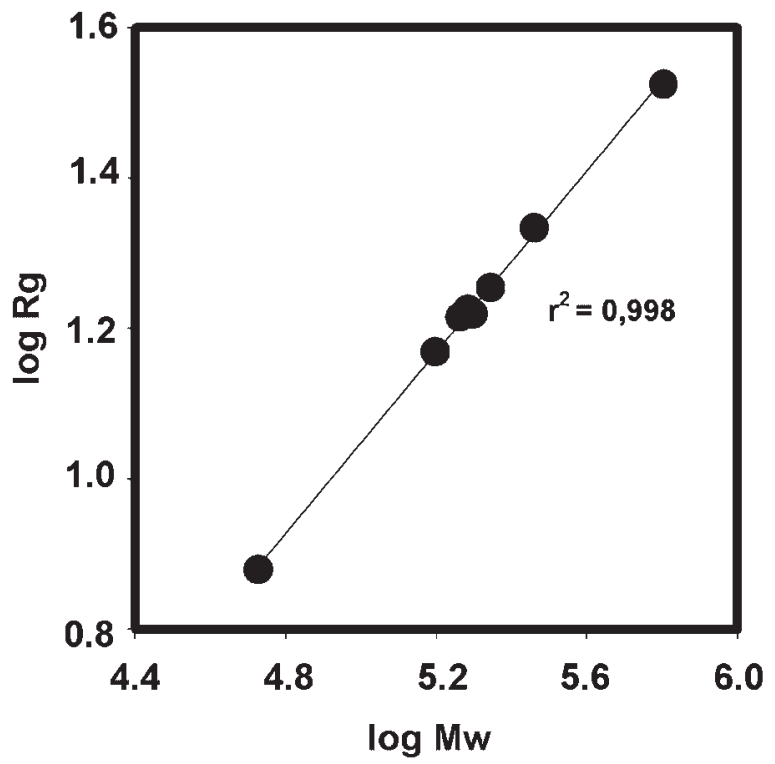

Figure 6. Plot of log radius of gyration against log molecular weight for PLA prepared by SET/DTLRP at $35^{\circ} \mathrm{C}$. 


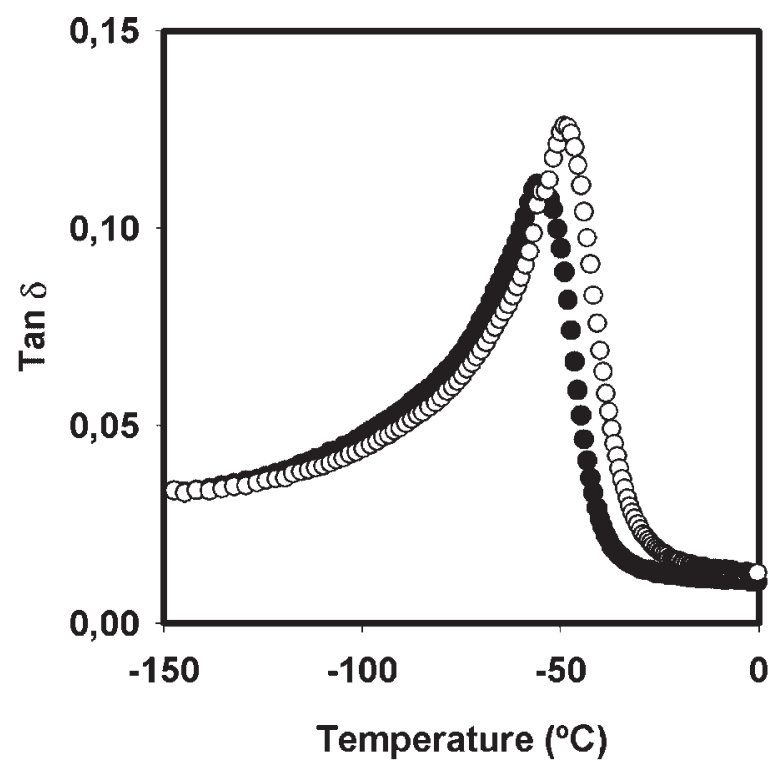

Figure 7. DMTA trace of PLA $\left(\bar{M}_{\mathrm{n}, \text { Trisec }}=50345 \mathrm{Da}, \bar{M}_{\mathrm{w}} / \bar{M}_{\mathrm{n}}=2.5\right)$ prepared at $35^{\circ} \mathrm{C}:(\bullet) 1 \mathrm{~Hz}$ and $10 \mathrm{~Hz}(\bigcirc)$.

the resultant deformation, while the sample is subjected to a controlled temperature program.

The DMTA was carried out in the constrain layer damping mode, which was previously used by the authors for different materials with high levels of success. ${ }^{[20,21,42]}$

Figure 7 shows a peak of $\tan \delta(1 \mathrm{HZ})$ at $-55^{\circ} \mathrm{C}$ that is sensitive to the frequency, and for that reason can be ascribed to the glass transition temperature.

\section{Conclusion}

The results obtained from this work show the possibility of using the SET/DTLRP method with all the advantages amply described in the literature ${ }^{[12,20-24]}$ for highly hydrophobic polar monomers. As the main conclusion, this approach allows the synthesis of $\alpha, \omega$-diiodoPLA that can be used as a macroinitiator for further functionalization or itself in macromolecular engineering

Received: January 10, 2007; Revised: March 16, 2007; Accepted: March 20, 2007; DOI: 10.1002/macp. 200700015

Keywords: degenerative chain transfer; lauryl acrylate; living polymerization; single electron transfer; tacticity; telechelics

[1] J. Jang, B.-S. Kim, J. Appl. Polym. Sci. 2000, 77, 903.

[2] T. Çaykara, G. Birlik, Macromol. Mat. Eng. 2005, 290, 869
[3] B. L. Waguespack, S. A. Hodges, M. Bush, L. J. Sondergeld, M. M. Bushey, J. Chromatogr. A 2005, 1078, 171.

[4] G. E. Scott, E. Senogles, J. Macromol. Sci., Chem. 1970, A4, 1105.

[5] H. W. S. Hsieh, B. Post, J. Morawest, J. Polym. Sci. 1976, 14, 1241.

[6] X. Zhu, Y. Gu, Z. Cheng, J. Lu, J. Appl. Polym. Sci. 2004, 93, 1539.

[7] M. K. Georges, J. L. Lukkarila, A. R. Szkurhan, Macromolecules 2004, 37, 1297.

[8] C. Farcet, B. Charleux, R. Pirri, Macromolecules 2001, 34, 3823.

[9] K. Matyjaszewski, Y. Nakagawa, C. B. Jasieczek, Macromolecules 1998, 31, 1535.

[10] Y. Fuji, T. Ando, M. Kamigaito, M. Sawamoto, Macromolecules 2002, 35, 2949.

[11] K. Beers, K. Matyjaszewski, J. Macromol. Sci. -Pure Appl. Chem. 2001, A38, 731.

[12] V. Percec, A. V. Popov, E. Ramirez-Castilho, J. F. J. Coelho, L. A. Hinojosa-Falcon, J. Polym. Sci., Part A: Polym. Chem. 2004, 42, 6267.

[13] V. Percec, A. V. Popov, E. Ramirez-Castilho, M. Monteiro, B. Barboiu, O. Weichold, A. D. Asandei, C. M. Mitchell, J. Amer. Chem. Soc. 2002, 124, 4940.

[14] V. Percec, A. V. Popov, E. Ramirez-Castilho, O. Weichold, J. Polym. Sci., Part A: Polym. Chem. 2003, 41, 3283.

[15] V. Percec, T. Guliashvili, A. V. Popov, E. Ramirez-Castilho, J. Polym. Sci., Part A: Polym. Chem. 2005, 43, 1478.

[16] V. Percec, T. Guliashvili, A. V. Popov, J. Polym. Sci., Part A: Polym. Chem. 2005, 43, 1948.

[17] V. Percec, T. Guliashvili, A. V. Popov, (University of Pennsylvania). U.S. Patent Appl Publ 2005/0131186, Chem. Abstr. 2005, 143, 60398.

[18] V. Percec, E. Ramirez-Castilho, A. V. Popov, L. A. HinojosaFalcon, T. Guliashvili, J. Polym. Sci., Part A: Polym. Chem. 2005, 43, 2178.

[19] V. Percec, A. V. Popov, E. Ramirez-Castilho, O. Weichold, J. Polym. Sci., Part A: Polym. Chem. 2004, 42, 6364.

[20] J. F. J. Coelho, A. M. F. P. Silva, A. V. Popov, V. Percec, M. V. Abreu, P. M. O. F. Gonçalves, M. H. Gil, J. Polym. Sci., Part A: Polym. Chem. 2006, 44, 2809.

[21] J. F. J. Coelho, A. M. F. P. Silva, A. V. Popov, V. Percec, M. V. Abreu, P. M. O. F. Gonçalves, M. H. Gil, J. Polym. Sci., Part A: Polym. Chem. 2006, 44, 3001.

[22] J. F. J. Coelho, M. Carreira, A. V. Popov, P. M. O. F. Gonçalves, M. H. Gil, J. Vinyl Add. Tech. 2006, 12, 156.

[23] J. F. J. Coelho, PhD Thesis, University of Coimbra 2006.

[24] J. F. J. Coelho, M. Carreira, A. V. Popov, P. M. O. F. Gonçalves, M. H. Gil, Eur. Polym. J. 2006, 42, 2313.

[25] M. Tabuchi, T. Kawauchi, T. Kitayama, K. Hatada, Polymer 2002, 43, 7185.

[26] M. U. Beer, P. J. Wood, J. Weisz, Carbohydr. Polym. 1999, 39, 377.

[27] J. F. J. Coelho, P. M. F. O. Gonçalves, D. Miranda, M. H. Gil, Eur. Polym. J. 2006, 42, 751.

[28] M. C. Iovu, K. Matyjaszewski, Macromolecules 2003, 36, 9346.

[29] S. Gaynor, J.-L. Wang, K. Matyjaszewski, Macromolecules 1995, 28, 8051.

[30] A. Goto, K. Ohno, T. Fukuda, Macromolecules 1998, 31, 2809.

[31] M. Lansalot, F. Céline, B. Charleux, J.-P. Vairon, R. Pirri, Macromolecules 1999, 32, 7354.

[32] P. Li, K.-Y. Qiu, J. Polym. Sci., Part A: Polym. Chem. 2002, 40, 2093. 
[33] H. L. Hsieh, R. P. Quirk, "Anionic Polymerization Principles and Practical Applications", Marcel Dekker, New York 1996.

[34] K. Matyjaszewski, S. Gaynor, J.-S. Wang, Macromolecules 1995, 28, 2093.

[35] J. Qiu, B. Charleux, K. Matyjaszewski, Prog. Polym. Sci. 2001, 26, 2083.

[36] B. Yamada, P. B. Zetterlund, "Handbook of Radical Chemistry", K. Matyjaszeski, T. P. Davis, Eds., John Wiley \& Sons, New York 2002, p. 117.
[37] M. Szwarc, J. Polym. Sci., Part A: Polym. Chem. 1998, 36, ix.

[38] M. Szwarc, M. Levy, R. Milkovich, J. Amer. Chem. Soc. 1956, 78 , 2656.

[39] M. Szwarc, Nature 1956, 178, 1168.

[40] J. Brandrup, E. H. Immergut, Eds., "Polymer Handbook", Wiley, New York 1989.

[41] TriSEC GPC Software Manual; V. Corp., Ed. 1996, p. A2.

[42] K. S. C. R. Santos, J. F. J. Coelho, P. Ferreira, I. Pinto, S. Lorenzetti, E. I. Ferreira, O. Higa, M. H. Gil, Int. J. Pharm. 2006, 1-2, 37. 